\title{
Novel VDBA based universal filter topologies with minimum passive components
}

\author{
Musa Ali Albrni*,**, Mohammad Faseehuddin*****, Jahariah Sampe* and Sawal Hamid Md Ali**** \\ *Institute of Microengineering and Nanoelectronics (IMEN), University Kebangsaan Malaysia (UKM), Selangor, Malaysia \\ **Department of Electrical and Electronics Technology, The Higher Institute for Engineering Technology, Zliten - Libya \\ ***Department of Electronics \& Telecommunication, Symbiosis Institute of Technology (SIT), Symbiosis International (Deemed University), \\ Lavale, Pune, Maharashtra 412115, India \\ ****Department of Electrical, Electronic and Systems Engineering, University Kebangsaan Malaysia (UKM), Selangor, Malaysia \\ *Correspondent Author: jahariah@ukm.edu.my
}

Submitted: 09/10/2019

Revised: $\quad 31 / 03 / 2020$

Accepted: $08 / 07 / 2020$

\begin{abstract}
ABSTARCT
In this research, voltage differencing buffered amplifier (VDBA) is utilized in designing three novel multi-input single output (MISO) topologies of universal filters. The designed filters employ minimum number of passive components and did not require any passive component matching condition. Two of the designed filters can work in dual mode of operation simultaneously. The designed filters have inbuilt tunability property. The nonideal gain analysis and sensitivity analysis of the filters are also carried out to study the effect of process variations and process spread on the filter responses. The complete layout of the VDBA is designed using $0.18 \mu \mathrm{m}$ Silterra Malaysia process design kit (PDK) in Cadence design software. The parasitic extraction is done using Mentor graphics Calibre tool. The postlayout simulations bear close resemblance with the theoretical predictions.
\end{abstract}

Keywords: Current conveyor; Current mode; Filters; Voltage mode; Voltage differencing buffered amplifier.

\section{INTRODUCTION}

Analog filters are an integral part of almost every electronic system, and so their synthesis and development remain an ever-evolving field. The filters find a wide array of applications in phase locked loop, FM stereo demodulator, telecommunication systems, speech processing, radar, data acquisition systems, instrumentation systems, etc. (Mohan 2012; Raut and Swamy 2010; Senani et al. 2014). Portable and network connected medical devices for real time monitoring and diagnosis of diseases will be vital in detecting diseases for future medical observation system. To develop such a system, low power and low noise analog circuits, such as amplifiers and filters, are required for physiological signal acquisition and signal processing (Cheng and Li 2015). The filters are also vital parts in biomedical data acquisition systems like sensors for artificial kidney for blood flow and filtration rate detection (Selvarajan et al. 2018; Yunus et al. 2017).

The filters based on active elements are the most attractive in terms of area efficiency, low voltage low power operation, and applicability. Active filters can exhibit high/low impedance levels at the input and the output. They can be designed for any gain easily. The filter circuit using active elements is generally much simpler compared to passive filters especially in higher-order filter implementations. A number of analog building blocks (ABBs) are employed in designing active filters, the most attractive ABBs are current conveyor (CCII) (Garradhi et al. 2018), differential voltage current conveyor (DVCC) (Horng and Jhao 2013), extra x current conveyor transconductance amplifier (EXCCTA) (Faseehuddin et al. 2018), Current backward transconductance amplifier (CBTA) (Sagbas et al. 2010), differential difference current conveyor (DDCC) (Abaci and Yuce et al. 2019), and current differencing transconductance amplifier 
(CDTA) (Biolek 2003). The VDBA is another popular ABB (Yeşil et al. 2014) that is simple in design and shown to be versatile in realizing numerous applications. Several variants of the VDBA are also proposed in the literature like the voltage differencing inverting buffer amplifier (VDIBA) (Herencsar et al. 2013), fully balanced voltage differencing buffer amplifier (FB-VDBA) (Biolkova et al. 2009), etc. Given the flexibility of the VDBA, it has not been fully explored in designing filter applications. In this research, the VDBA is utilized in designing three novel filter structures.

The comparison of the filters can be done based on the following numerous criteria, which are important design parameters for comparison: (i) the number of ABBs employed; (ii) the number of passive elements used; (iii) the requirement of passive components matching condition; (iv) the low output impedance in case of VM and TIM filters/ high output impedance in case of CM and TAM filters; (v) inbuilt tunability; (vi) the use of negative or double input voltage for realizing filter responses; (vii) independent control of quality factor and pole frequency; (viii) the number of modes, in which they can work without any alteration in topology. The comparison of some exemplary MISO filter designs from literature with the proposed filters is given in Table 1.

Table 1. Comparative Study of the MISO Filters.

\begin{tabular}{|c|c|c|c|c|c|c|c|c|}
\hline Reference & (i) & (ii) & (iii) & (iv) & (v) & (vi) & (vii) & (viii) \\
\hline (Sagbas et al. 2010) & 1 & 4 & No & No & Yes & Yes & Yes & VM \\
\hline (Herencsar et al. 2010) & 1 & 4 & No & Yes & Yes & No & No & VM \\
\hline (Pandey and Paul 2011) & 1 & 3 & No & No & Yes & No & No & VM \\
\hline (Myderrizi et al. 2011) & 1 & 6 & No & No & No & Yes & Yes & VM \\
\hline (Tangsrirat and Channumsin 2011) & 1 & 4 & Yes & No & No & Yes & No & VM \\
\hline (Horng and Jhao 2013) & 1 & 4 & Yes & No & No & No & No & VM \\
\hline (Ninsraku et al.2014) & 2 & 2 & No & Yes & Yes & Yes & Yes & VM \\
\hline (Lee 2017) & 3 & 7 & No & No & No & No & Yes & VM \\
\hline (Ranjan 2018) & 1 & 4 & No & No & No & Yes & No & VM \\
\hline (Yuce and Tez 2018) & 2 & 5 & Yes & Yes & No & Yes & Yes & VM \\
\hline (Uttaphut 2018) & 1 & 3 & No & Yes & Yes & Yes & No & VM \\
\hline (Singh and Nagaria 2020) & 1 & 3 & Yes & Yes & Yes & Yes & No & CM \\
\hline (Kumar et al. 2019) & 1 & 2 & Yes & No & Yes & Yes & Yes & VM \\
\hline (Basak 2019) & 1 & 5 & Yes & No & Yes & Yes & Yes & VM \\
\hline $\begin{array}{c}\text { Authors Work } \\
\text { Figure 4 }\end{array}$ & 3 & 2 & No & Yes & Yes & No & Yes & VM, TAM \\
\hline Authors Work & 3 & 3 & No & Yes & Yes & No & No & CM, TIM \\
\hline Figure 5 & 1 & 3 & No & Yes & Yes & Yes & No & VM \\
\hline
\end{tabular}

It can be deduced from the comparison that the proposed designs hold advantages over the most other designs.

In this research, three novel topologies of VDBA based universal filters are developed. None of the proposed filters require any passive component matching conditions for response realization. Moreover, two of the proposed filters can work in dual mode simultaneously. The complete layout of the VDBA is designed using $0.18 \mu \mathrm{m}$ Silterra Malaysia PDK in Cadence design software. The postlayout results are given for all the designs. 


\section{Voltage Differencing Buffered Amplifier (VDBA)}

The VDBA is a popular ABB that is simple in design and is shown to be versatile in realizing numerous applications. The VDBA consists of an operational transconductance amplifier (OTA) as the input stage and voltage buffer as the output stage. The V-I relations of the VDBA are summarized in Equation 1 and the block diagram is shown in Figure 1.

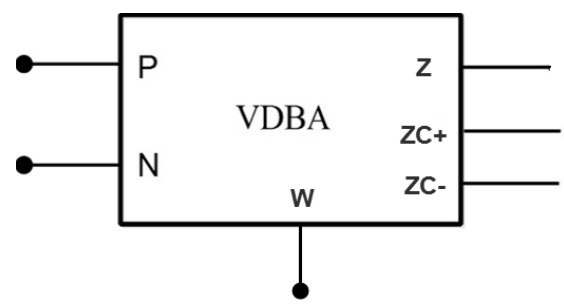

Figure 1. Block Diagram of VDBA.

$$
\left[\begin{array}{c}
I_{P} \\
I_{N} \\
I_{Z} \\
I_{Z C+} \\
I_{Z C-} \\
V_{W}
\end{array}\right]=\left[\begin{array}{ccc}
0 & 0 & 0 \\
0 & 0 & 0 \\
g_{m} & -g_{m} & 0 \\
g_{m} & -g_{m} & 0 \\
-g_{m} & g_{m} & 0 \\
0 & 0 & 1
\end{array}\right]\left[\begin{array}{l}
V_{P} \\
V_{N} \\
V_{Z}
\end{array}\right]
$$

The CMOS implementation of VDBA is shown in Figure 2. It is a six terminal device. It is also worth mentioning that the number of $Z$ terminals can be increased by just adding two additional CMOS transistors without affecting the functionality of the ABBs. The transistors (M1-M14) form the OTA which is the first stage of the VDBA. The output current of the OTA depends on the voltage difference between voltage at terminals $P$ and $N$. Assuming saturation region operation for all transistors and equal $\mathrm{W} / \mathrm{L}$ ratio for transistors $\mathrm{M} 1$ and $\mathrm{M} 2$ the output current $I_{Z}=I_{Z C+}=-I_{Z C-}$ of the OTA is given by Equation 2.

$$
I_{Z}=I_{Z C+}=-I_{Z C-}=g_{m}\left(V_{P}-V_{N}\right)=\left(\sqrt{2 I_{\text {Bias }} k}\right)\left(V_{P}-V_{N}\right)
$$

Where, the transconductance parameter $\mathrm{K}_{\mathrm{i}}=\mu \mathrm{C}_{\mathrm{ox}} \mathrm{W} / 2 \mathrm{~L}(\mathrm{i}=1,2), \mathrm{W}$ is the effective channel width, $\mathrm{L}$ is the effective length of the channel, $\mathrm{C}_{\mathrm{ox}}$ is the gate oxide capacitance per unit area and $\mu$ is the carrier mobility.

The second stage consists of a voltage follower designed using transistors (M15-M21). The nodes Z, ZC+, ZC- are high impedance nodes, and the $\mathrm{W}$ node is the low impedance voltage output node. The negative feedback from M20 and M21 reduces the resistance of the $\mathrm{W}$ node making it low impedance.

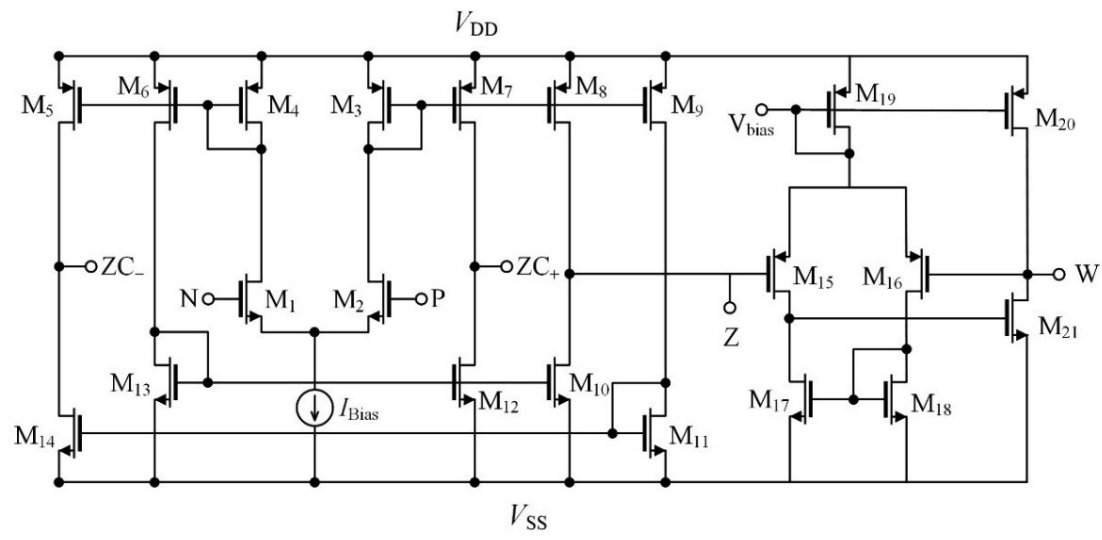

Figure 2. CMOS implementation of VDBA. 


\section{Layout Design}

The complete layout of the VDBA is designed using Silterra Malaysia $0.18 \mu \mathrm{m}$ PDK in Cadence Virtuoso design software. The high performance nhp and php MOS transistors from the Silterra library are used for the design. To minimize the effect of parasitics, the transistors are put as close as possible. Two levels of metal layers are used for the interconnections. The complete layout is presented in Figure 3. The layout occupies an area of $27.68 \mu \mathrm{m} * 24.25 \mu \mathrm{m}$.

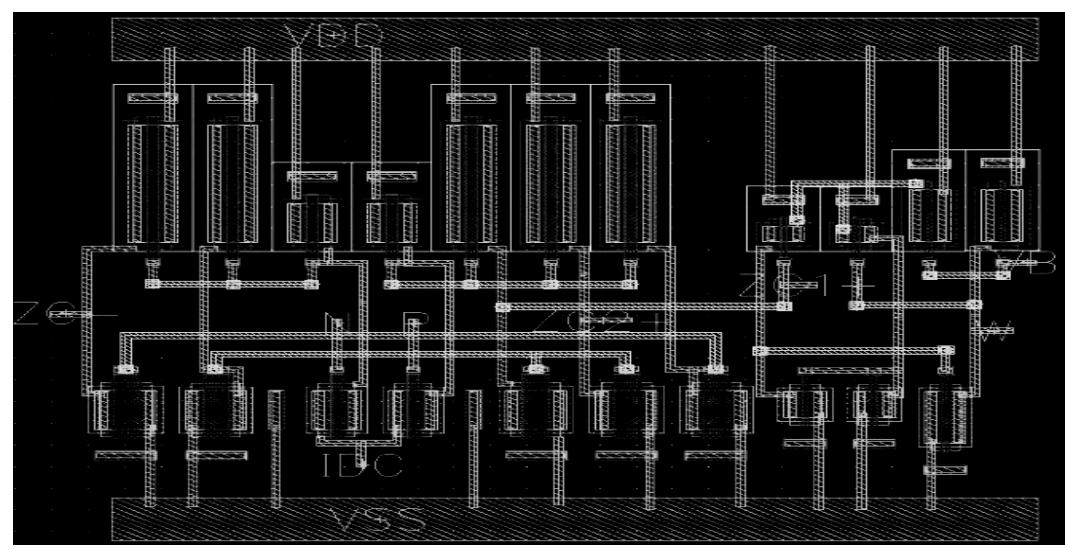

Figure 3. Layout of the VDBA.

\section{Proposed Universal Filters}

In this research, three minimum component MISO universal filters are proposed. The proposed filters did not require any passive component matching conditions and provide low output impedance in case of voltage mode output and high impedance in case of current mode output; hence, they are cascadable.

\subsection{Dual Mode Voltage Mode and Transadmittance Mode Filter}

A dual mode filter employing three VDBAs is presented in Figure 4. The proposed filter is resistor less and utilize only two capacitors as passive elements. In the implementation, one of the capacitors is grounded, which is advantageous for fabrication, as well as for noise cancellation. The filter can work in two modes of operation, namely, VM and TAM, and can provide the VM and TAM output simultaneously. The features of the filter include inbuilt tunability, independent control of quality factor and pole frequency, dual mode of operation, availability of explicit current output from high impedance node and voltage output from low impedance node simultaneously, use of only two passive elements, resistorless implementation and no requirement of negative or double input signals to realize filter responses.

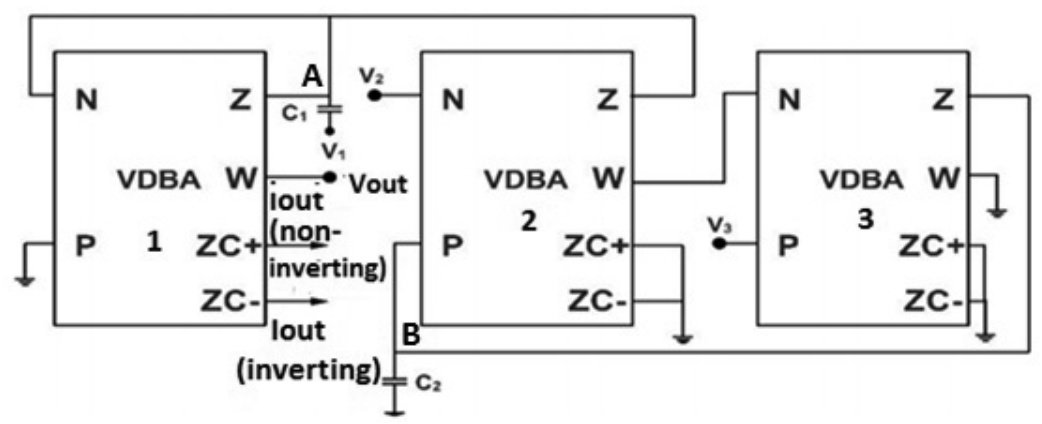

Figure 4. VM and TAM dual mode universal filter. 
The filter transfer functions are given in Equations 11 and 13 and expressions for pole frequency and quality factor are summarized in Equations 16-17. The transconductance of the VDBA is represented by $g_{m}(\mathrm{~m}=1,2$ and 3$)$. The $g_{m}$ is varied by changing the bias current of the OTA $\left(I_{\text {bias } 1}, I_{\text {bias } 2}\right.$ and $\left.I_{\text {bias } 3}\right)$ providing tunability to the filter.

The procedure adopted to evaluate the transfer function of the filter is explained below. According to the V-I relation of VDBA, the following relations are derived.

$$
I_{Z}=I_{Z C+}=-I_{Z C-}=g_{m}\left(V_{P}-V_{N}\right)
$$

$V_{Z}=V_{W}$

Applying KCL at node A

$-V_{\text {out }} g_{1}+\left(V_{B}-V_{2}\right) g_{2}=\left(V_{\text {out }}-V_{1}\right) s C_{1}$

$V_{B} g_{2}-V_{2} g_{2}+V_{1} s C_{1}=V_{\text {out }} s C_{1}+V_{\text {out }} g_{1}$

Applying KCL at node B

$\left(V_{3}-V_{\text {out }}\right) g_{3}=V_{B} s C_{2}$

$V_{B}=\frac{\left(V_{3} g_{3}-V_{\text {out }} g_{3}\right)}{s C_{2}}$

Putting the value of Equation 8 in Equation 6, we get

$\frac{V_{3} g_{3} g_{2}}{s C_{2}}-\frac{V_{\text {out }} g_{3} g_{2}}{s C_{2}}-V_{2} g_{2}+V_{1} s C_{1}=V_{\text {out }} s C_{1}+V_{\text {out }} g_{1}$

Reorganizing the terms to get $V_{\text {out }}$ leads to

$$
\begin{aligned}
& V_{\text {out }}=\frac{\frac{S^{2} C_{1} C_{2}}{g_{2} g_{3}} V_{1}-\frac{S C_{2} g_{2}}{g_{2} g_{3}} V_{2}+V_{3}}{\frac{S^{2} C_{1} C_{2}}{g_{2} g_{3}}+\frac{S C_{2} g_{1}}{g_{2} g_{3}}+1} \\
& V_{\text {out }}=\frac{S^{2} C_{1} C_{2} V_{1}-S C_{2} g_{2} V_{2}+g_{2} g_{3} V_{3}}{S^{2} C_{1} C_{2}+S C_{2} g_{1}+g_{2} g_{3}} \\
& I_{\text {out }}=I_{Z C+}=I_{Z C-}=g_{1} V_{\text {out }} \\
& I_{\text {out }}=g_{1}\left[\frac{S^{2} C_{1} C_{2} V_{1}-S C_{2} g_{2} V_{2}+g_{2} g_{3} V_{3}}{S^{2} C_{1} C_{2}+S C_{2} g_{1}+g_{2} g_{3}}\right] \\
& D(s)=S^{2} C_{1} C_{2}+S C_{2} g_{1}+g_{2} g_{3} \\
& D(s)=S^{2}+s \frac{g_{1}}{C_{1}}+\frac{C_{1} C_{2}}{g_{2} g_{3}} \\
& \omega_{o}=\sqrt{\frac{g_{2} g_{3}}{C_{1} C_{2}}}
\end{aligned}
$$


$Q=\frac{1}{g_{1}} \sqrt{\frac{g_{2} g_{3} C_{1}}{C_{2}}}$

Table 2 provides the excitation sequence of the filter for response realization.

Table 2. Input voltage excitation sequence.

\begin{tabular}{|c|c|c|c|}
\hline Response & \multicolumn{3}{|c|}{ Inputs } \\
\hline & $\boldsymbol{V}_{\boldsymbol{1}}$ & $\boldsymbol{V}_{\boldsymbol{2}}$ & $\boldsymbol{V}_{\boldsymbol{3}}$ \\
\hline LP & 0 & 0 & 1 \\
\hline HP & 1 & 0 & 0 \\
\hline BP & 0 & 1 & 0 \\
\hline NP & 1 & 0 & 1 \\
\hline AP & 1 & 1 & 1 \\
\hline
\end{tabular}

\subsection{Dual Mode Current Mode and Transimpedance Mode Filter}

A dual mode filter employing three VDBAs is presented in Figure 5. The proposed filter utilizes two capacitors and a single resistor as passive element. In the implementation, both the capacitors are grounded, which is advantageous for fabrication, as well as for noise cancellation. The filter can work in two modes of operation namely, CM and TIM, and can provide the CM and TIM outputs simultaneously. The features of the filter include inbuilt tunability, use of grounded passive elements, dual mode of operation, availability of explicit current output from high impedance node and voltage output from low impedance node simultaneously and no requirement of negative or double input signals to realize filter responses.

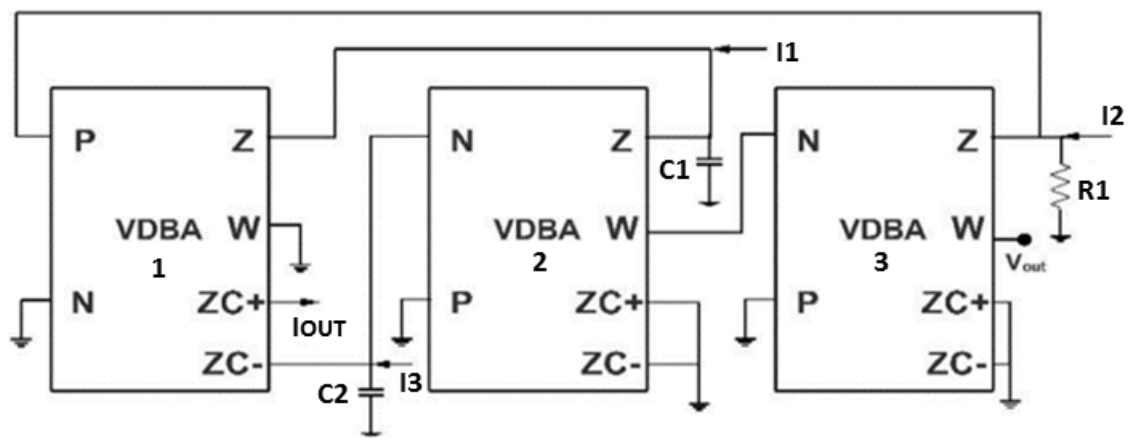

Figure 5. CM and TIM dual mode universal filter.

The filter transfer function and expressions for pole frequency and quality factor are summarized in Equations 1821. To realize a filter with unit gain, $\left(\boldsymbol{g}_{\mathbf{2}} \boldsymbol{R}_{\mathbf{1}}=\mathbf{1}\right)$ must be satisfied. The transconductance of the VDBA is represented by $\boldsymbol{g}_{\boldsymbol{m}}\left(\mathrm{m}=1,2\right.$ and 3). The $\boldsymbol{g}_{\boldsymbol{m}}$ is varied by changing the bias current of the OTA $\left(\boldsymbol{I}_{\text {bias } \mathbf{1}}, \boldsymbol{I}_{\text {bias } \mathbf{2}}\right.$ and $\left.\boldsymbol{I}_{\text {bias } \mathbf{3}}\right)$ providing tunability to the filter. To design the filter for unity gain $\boldsymbol{g}_{1}=\boldsymbol{g}_{2}$ is kept and $\boldsymbol{g}_{3}$ is varied to change the frequency of operation.

$$
I_{\text {out }}=g_{2} R_{1}\left[\frac{S^{2} C_{1} C_{2} I_{2}-S C_{2} g_{1} I_{1}+g_{3} g_{1} I_{3}}{S^{2} C_{1} C_{2}+S C_{2} g_{1} g_{2} R_{1}+g_{1} g_{3} g_{2} R_{1}}\right]
$$


$V_{\text {out }}=R_{1}\left[\frac{\left(S^{2} C_{1} C_{2} / g_{3} g_{1}\right) I_{2}-\left(S C_{2} / g_{3}\right) I_{1}+I_{3}}{S^{2} C_{1} C_{2} / g_{3} g_{1} g_{2} R_{1}+S C_{2} / g_{3}+1}\right]$

$\omega_{o}=\sqrt{\frac{g_{3} g_{1} g_{2} R_{1}}{C_{1} C_{2}}}$

$Q=\sqrt{\frac{g_{3} C_{1}}{g_{2} g_{1} C_{2} R_{1}}}$

Table 3 provides the excitation sequence for the filter for response realization.

Table 3. Input current excitation sequence.

\begin{tabular}{|c|c|c|c|}
\hline Response & \multicolumn{3}{|c|}{ Inputs } \\
\hline & $\boldsymbol{I}_{\boldsymbol{1}}$ & $\boldsymbol{I}_{\mathbf{2}}$ & $\boldsymbol{I}_{\boldsymbol{3}}$ \\
\hline $\mathrm{LP}$ & 0 & 0 & 1 \\
\hline $\mathrm{HP}$ & 0 & 1 & 0 \\
\hline $\mathrm{BP}$ & 1 & 0 & 0 \\
\hline $\mathrm{NP}$ & 0 & 1 & 1 \\
\hline $\mathrm{AP}$ & 1 & 1 & 1 \\
\hline
\end{tabular}

\subsection{Voltage Mode Filter}

The proposed filter using the VDBA is shown in Figure 6. The filter makes use of a single VDBA, two capacitors, and a resistor and can realize all five filter functions by appropriately applying the input signals. The filter did not require any passive components matching condition for response realization. In addition, the filter output is available from low impedance node. A number of variants of VDBA can be found in the literature like VDIBA and FB-VDBA but none of the single active block based filters proposed using them enjoys the feature of low output impedance.

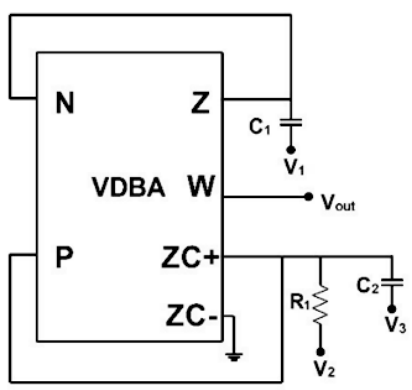

Figure 6. VM universal filter.

The filter transfer function and expressions for pole frequency and quality factor are summarized in Equations 2224. The input sequence is given in Table 4. The filter requires a simple active matching condition of $\left(\boldsymbol{g}_{\mathbf{1}} * \boldsymbol{R}_{\mathbf{1}}=\mathbf{1}\right)$. This can be easily met by selecting $\boldsymbol{R}_{\mathbf{1}}$ and then adjusting the bias current of the OTA to satisfy the condition. 


$$
\begin{aligned}
& V_{\text {out }}=\frac{S^{2} C_{1} C_{2} R_{1} / g_{1} V_{1}+S C_{2} R_{1} V_{3}+V_{2}}{S^{2} C_{1} C_{2} R_{1} / g_{1}+S C_{2} R_{1}+1} \\
& \omega_{o}=\sqrt{\frac{g_{1}}{R_{1} C_{2} C_{1}}} \\
& Q=g_{1} \sqrt{\frac{C_{1}}{C_{2} R_{1}}}
\end{aligned}
$$

Table 4. Input voltage excitation sequence.

\begin{tabular}{|c|c|c|c|c|}
\hline Response & \multicolumn{3}{|c|}{ Inputs } & Active Matching Condition \\
\hline & $\boldsymbol{V}_{\mathbf{1}}$ & $\boldsymbol{V}_{\mathbf{2}}$ & $\boldsymbol{V}_{\mathbf{3}}$ & \\
\hline LP & 0 & 1 & 0 & $g_{1} * R_{1}=1$ \\
\hline HP & 1 & 0 & 0 & $g_{1} * R_{1}=1$ \\
\hline BP & 0 & 0 & 1 & $g_{1} * R_{1}=1$ \\
\hline NP & 1 & 1 & 0 & $g_{1} * R_{1}=1$ \\
\hline AP & 1 & 1 & -1 & $g_{1} * R_{1}=1$ \\
\hline
\end{tabular}

\section{Non-Ideal Analysis}

The nonideal model of the VDBA is presented in Figure 7. As can be deduced from the figure, the various parasitic resistance and capacitance appear in parallel with the input and output nodes of the device. The low impedance $\mathrm{X}$ node has a parasitic resistance and inductance in series with it.

The other nonideal effects that influence the response of the VDBA are the frequency dependent nonideal voltage $(\beta)$ and transconductance transfer $\left(\gamma / \gamma^{\prime}\right)$ gains. These gains cause a slight change in the current and voltage signals during transfer leading to undesired response. Taking into account the nonideal gains, the V-I characteristics of the VDBA will be modified as follows.

$$
\begin{aligned}
& I_{Z}=I_{Z C}=\gamma g_{m}\left(V_{P}-V_{N}\right) \\
& I_{Z C-}=\gamma^{\prime} g_{m}\left(V_{P}-V_{N}\right) \\
& V_{Z}=\beta V_{W}
\end{aligned}
$$

The nonideal analysis considering the effect of nonideal current and voltage transfer gains is carried out for all the proposed filters to see its effect on the transfer function, pole frequency and quality factor of the proposed filters. The modified expressions of filter transfer function, quality factor, and pole frequency for all the three design are presented below. The nonidealities result in deviations from the expected value. 


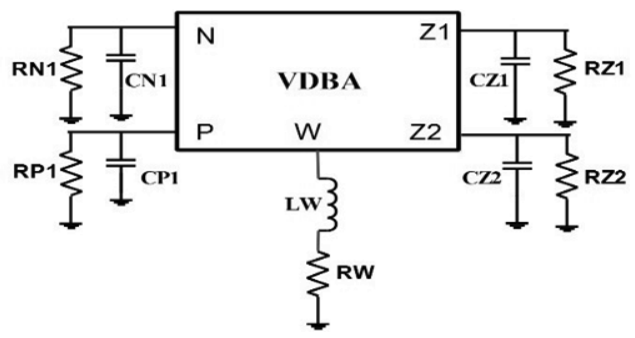

Figure 7. Nonideal Model of VDBA.

Nonideal results for the dual mode VM and TAM filter are given in Equations 28-30. The analysis results for dual mode CM and TIM filter are given in Equations 31-33. The nonideal analysis results for the VM single VDBA filter are presented in Equations 34-36.

$$
\begin{aligned}
& V_{\text {out }}=\frac{S^{2} C_{1} C_{2} V_{1}-S \gamma C_{2} g_{2} V_{2}+\gamma^{2} g_{2} g_{3} V_{3}}{S^{2} \beta C_{1} C_{2}+S \beta \gamma C_{2} g_{1}+\gamma^{2} g_{2} g_{3}} \\
& \omega_{o}=\gamma \sqrt{\frac{g_{2} g_{3}}{\beta C_{1} C_{2}}} \\
& Q=\frac{1}{g_{1}} \sqrt{\frac{g_{2} g_{3} C_{1}}{\beta C_{2}}} \\
& I_{\text {out }}= \\
& \left.\omega_{o}=\sqrt{\left.\frac{\beta \gamma g_{2} R_{1}\left[\frac{S_{1} g_{2} R_{1}}{C_{1} C_{2}}\right.}{S_{1} C_{2}+S \gamma \beta C_{2} g_{1} g_{2} R_{1}+\gamma \beta g_{1} g_{3} g_{2} R_{1}}\right]}\right] \\
& \omega_{o}=\sqrt{\frac{\gamma \gamma g_{1}}{R_{1} C_{2} C_{1}}} \\
& V_{\text {out }}=\frac{\sqrt{\frac{\gamma g_{3} C_{1} g_{1} C_{2} R_{1}}{C_{2} R_{1}}}}{\left(S^{2} C_{1} C_{2} R_{1} / \gamma g_{1} C_{2} \beta / \gamma g_{1}+S C_{2} \beta+S C_{1} \beta / \gamma R_{1} g_{1}-S C_{1} \beta+\frac{\beta}{R_{1}}\right.}
\end{aligned}
$$


As a result of component tolerance and nonidealities in VDBA, the response of the practical filter deviates from the ideal one. To get a measure of the deviation, the concept of sensitivity is employed. Mathematically, sensitivity is defined as $S_{x}^{y}=\lim _{\Delta X-\infty}\left\{\frac{\Delta y / y}{\Delta x / x}\right\}=\frac{x}{y} \frac{\partial y}{\partial x}$, where $\mathrm{X}$ is the component that is varied, and $\mathrm{Y}$ is the filter frequency $\left(\omega_{P}\right)$ and quality factor $\mathrm{Q}$ in our case.

The sensitivities of $\omega_{o}$ and $Q$ with respect to the nonideal gain and passive elements are given below. The sensitivities for the dual mode VM and TAM filter are given in Equations 37-40. The sensitivity analysis results for dual mode $\mathrm{CM}$ and TIM filter are given in Equations 41-42. The sensitivities for the VM single VDBA filter are presented in Equations 43-45. The sensitivities are not more than one, which is desired.

$$
\begin{aligned}
& -S_{C_{1}}^{\omega}=-S_{C_{2}}^{\omega}=S_{\beta}^{\omega}=S_{g_{3}}^{\omega}=S_{g_{2}}^{\omega}=\frac{1}{2} \\
& S_{\gamma}^{\omega}=1 \\
& S_{C_{1}}^{Q}=S_{g_{3}}^{\omega}=S_{g_{2}}^{\omega}=-S_{C_{2}}^{Q}=-S_{\beta}^{Q}=\frac{1}{2} \\
& S_{g_{1}}^{Q}=1 \\
& S_{\beta}^{\omega}=S_{\gamma}^{\omega}=S_{g_{1}}^{\omega}=-S_{g_{2}}^{\omega}-S_{g_{3}}^{\omega}=-S_{C_{2}}^{\omega}=S_{R_{1}}^{\omega}=-S_{C_{1}}^{\omega}=\frac{1}{2} \\
& S_{g_{3}}^{Q}=S_{C_{1}}^{Q}=-S_{C_{2}}^{Q}=-S_{\beta}^{Q}-S_{\gamma}^{Q}=-S_{g_{2}}^{Q}=-S_{g_{1}}^{Q}=-S_{R_{1}}^{Q}=\frac{1}{2} \\
& -S_{C_{1}}^{\omega}=-S_{C_{2}}^{\omega}=-S_{R_{1}}^{\omega}=S_{\gamma}^{\omega}=S_{g_{1}}^{\omega}=\frac{1}{2} \\
& S_{C_{1}}^{Q}=-S_{C_{2}}^{Q}=-S_{R_{1}}^{Q}=\frac{1}{2} \\
& S_{g_{1}}^{Q}=1
\end{aligned}
$$

\section{Post Layout Simulation Results}

To examine the designed filters, the VDBA is designed using $0.18 \mu \mathrm{m}$ Silterra Malaysia PDK in Cadence Virtuoso design software. The parasitic extraction was done using the Mentor Calibre tools. The width and length ratios of the VDBA are given in Table 5 . The supply voltage is set at $\pm 1.25 \mathrm{~V}$, and the OTA bias current was fixed at $100 \mu \mathrm{A}$. Table 6 gives the performance metrics of the designed VDBA.

Table 5. Width and length of the MOS transistors.

\begin{tabular}{|c|c|c|}
\hline Transistor & Width $(\boldsymbol{\mu m})$ & Length $(\boldsymbol{\mu m})$ \\
\hline M1-M4 & 1.8 & 0.36 \\
\hline M5-M9 & 5.4 & 0.36 \\
\hline M11-M14 & 1.8 & 0.36 \\
\hline M15-M16 & 1.8 & 0.36 \\
\hline M17-M18 & 1.2 & 0.36 \\
\hline M21 & 2.4 & 0.36 \\
\hline M19-M20 & 4.8 & 0.36 \\
\hline
\end{tabular}


Table 6. Performance parameters of the designed VDBA.

\begin{tabular}{|c|c|}
\hline Parameters & Silterra 0.18 $\boldsymbol{\mu m}(\mathbf{V D D}=\mathbf{V S S}=\mathbf{1 . 2 5} \mathbf{)}$ \\
\hline Voltage gain $\left(V_{W} / V_{Z}\right)$ & 0.985 \\
\hline Voltage transfer Bandwidth $\left({ }^{V_{W}} / V_{Z}\right)$ & $3.0262 \mathrm{GHz}$ \\
\hline DC Voltage Range $\left(V_{Z}-V_{W}\right)$ & $\pm 900 \mathrm{mV}$ \\
\hline Static Power Dissipation & $1.618 \mathrm{~mW}$ \\
\hline Parasitic Resistance at node $(\mathrm{RW})$ & $140.89 \Omega$ \\
\hline ZC+ node resistance & $64.4 \mathrm{k} \Omega$ \\
\hline ZC- node resistance & $64.4 \mathrm{k} \Omega$ \\
\hline
\end{tabular}

The dual mode VM and TAM MISO filter presented in Figure 4 is validated first by designing it for -3dB cutoff frequency of 7.213 MHz and quality factor of one. According to Equations 16-17 the passive elements are selected as follows $C_{1}=20 \mathrm{pF}$ and $C_{2}=20 \mathrm{pF}$. The OTA bias current for all the three VDBA is set at $100 \mu \mathrm{A}$ to achieve $g_{m(1-3)}$ $=906.53 \mu \mathrm{S}$. The ideal and postlayout frequency response of the filter is given in Figure 8 and the AP response is shown in Figure $9(\mathrm{a}-\mathrm{b})$. The power dissipation of the filter for bias current of $80 \mu \mathrm{A}$ for all three VDBA is found to $5.47 \mathrm{~mW}$.

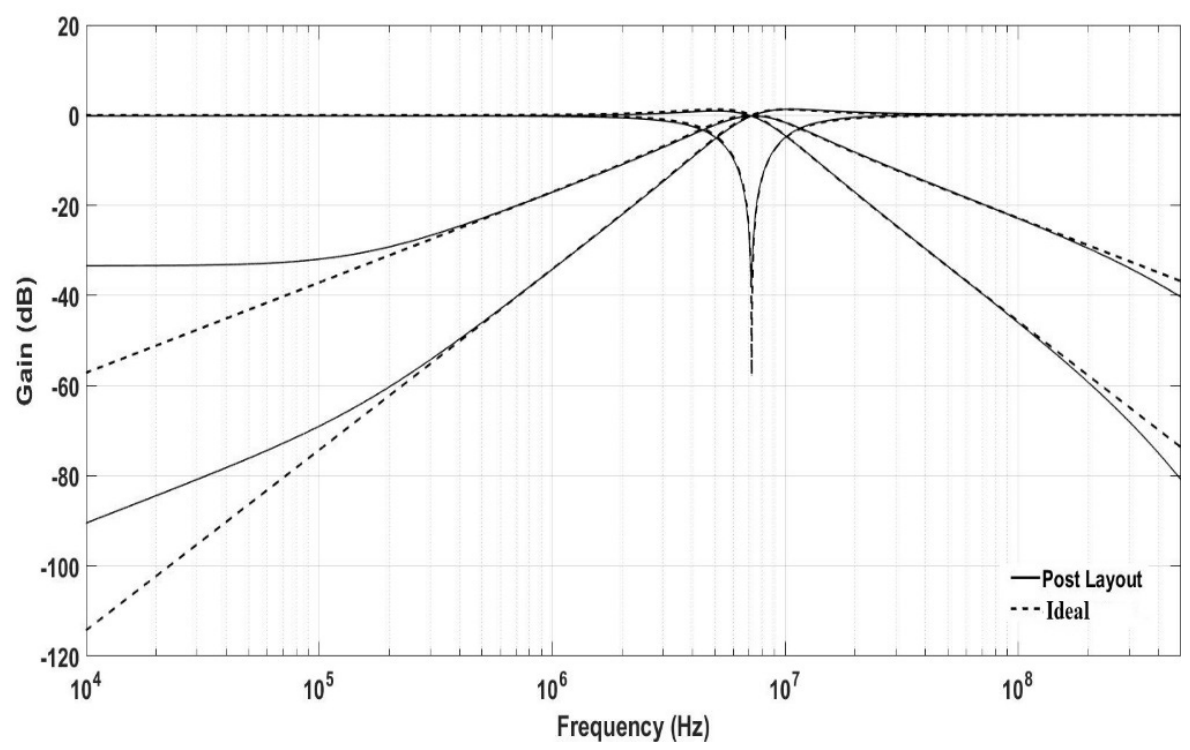

Figure 8. VM response of the dual mode filter. 


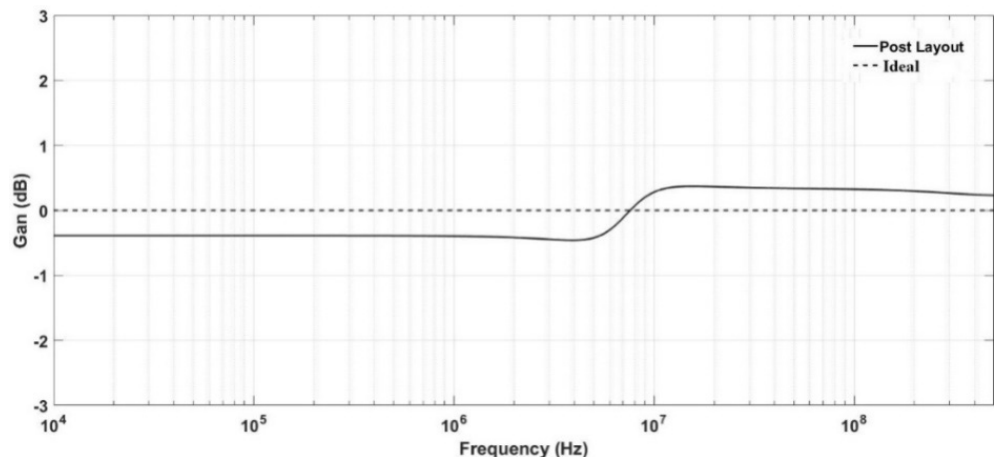

(a)

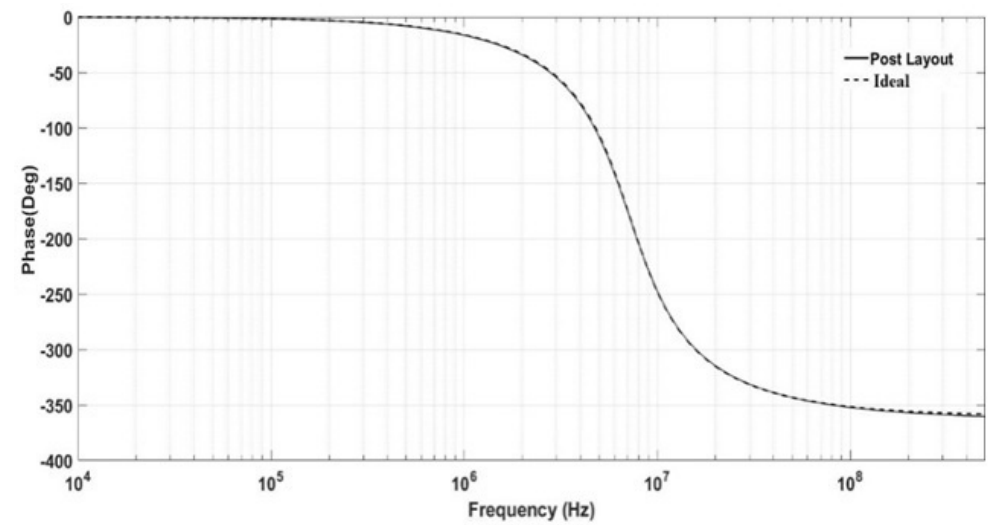

(b)

Figure 9. VM all pass response of the dual mode filter (a) Magnitude (b) Phase.

To validate the signal processing capability of the filter, a transient analysis is carried out. A $100 \mathrm{mV}$ input signal at 7.21 MHz frequency is applied, and the BP output is observed. It can be inferred from Figure 10 that the filter functions correctly. In addition, the quality factor tuning is tested by varying the OTA bias current of first VDBA of the MISO filter. According to Equations 16-17, the quality factor can be tune independent of frequency as can be observed from Figure 11. The total harmonic distortion (THD) is measured for BP configuration. The THD remains within 6\% till $250 \mathrm{mV}$ input voltage range.

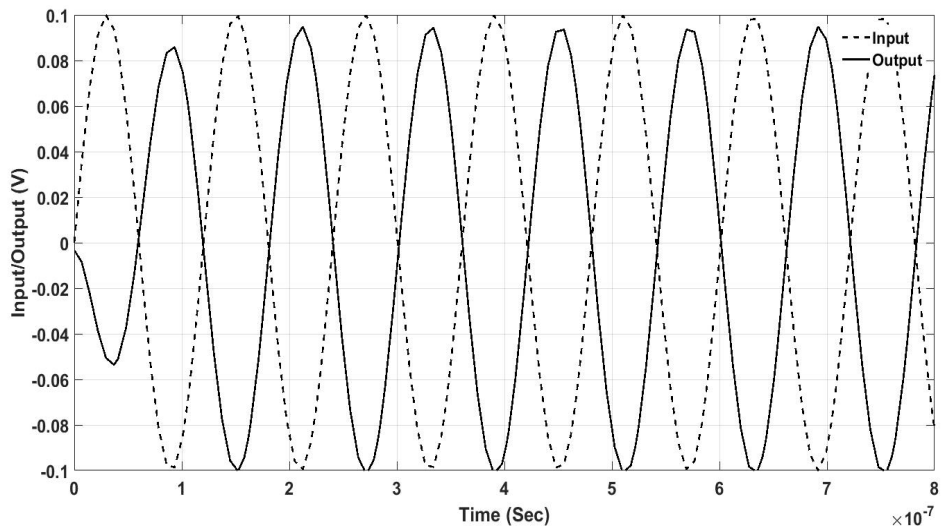

Figure 10. Transient analysis of the VM filter. 


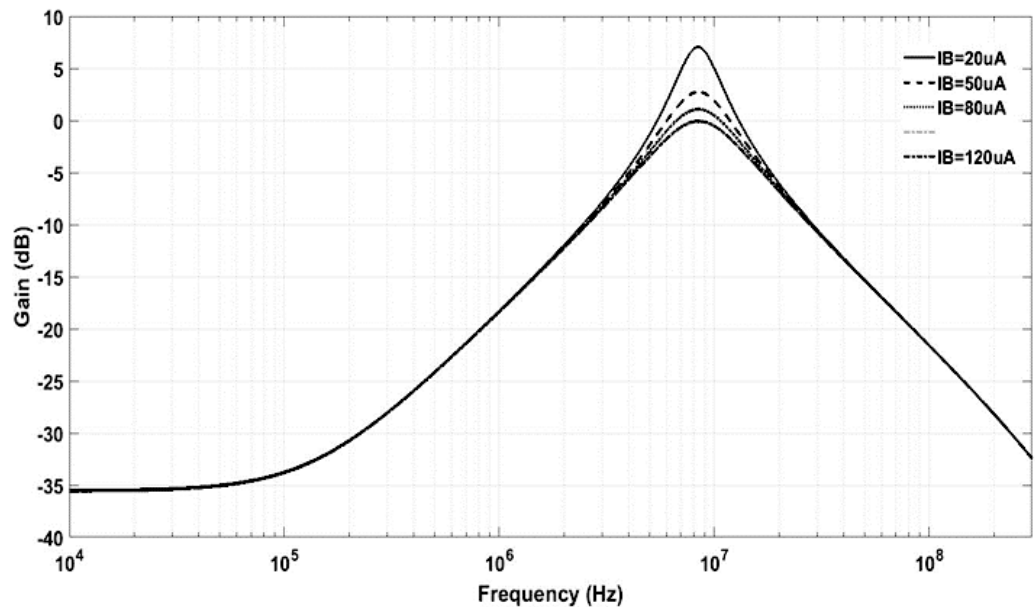

Figure 11. TAM response of the dual mode filter.

The TAM mode postlayout frequency responses of the filter are presented in Figure 12 and 13 at the designed frequency of 7.213 MHz. These pre- and postlayout results validate that the filter can work in dual mode simultaneously.

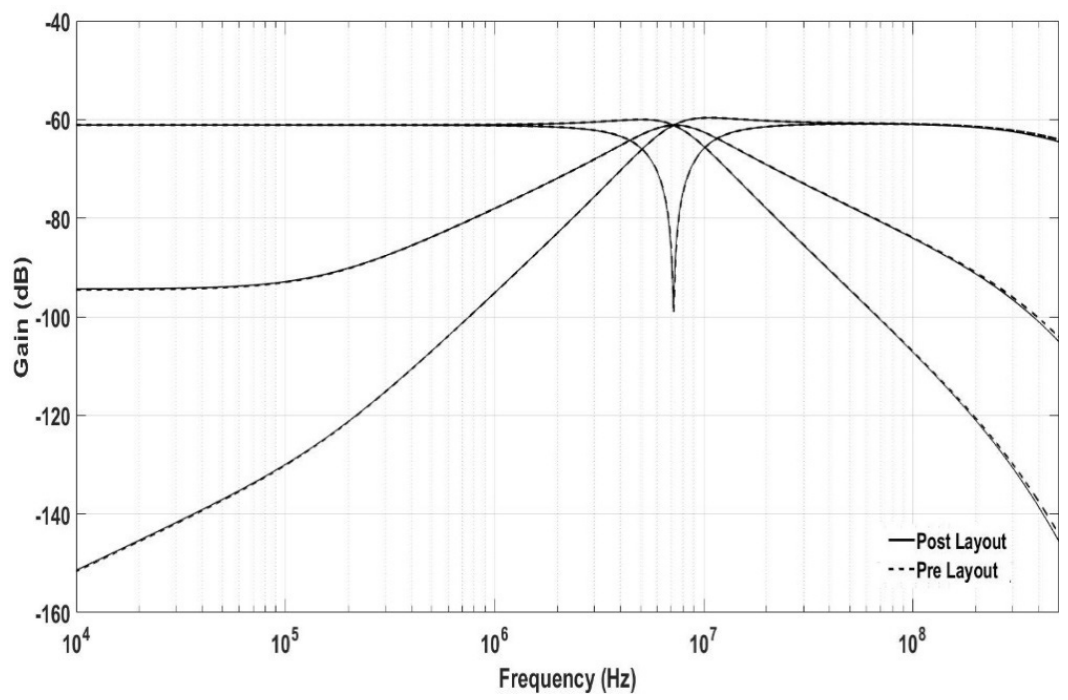

Figure 12. TAM response of the dual mode filter. 


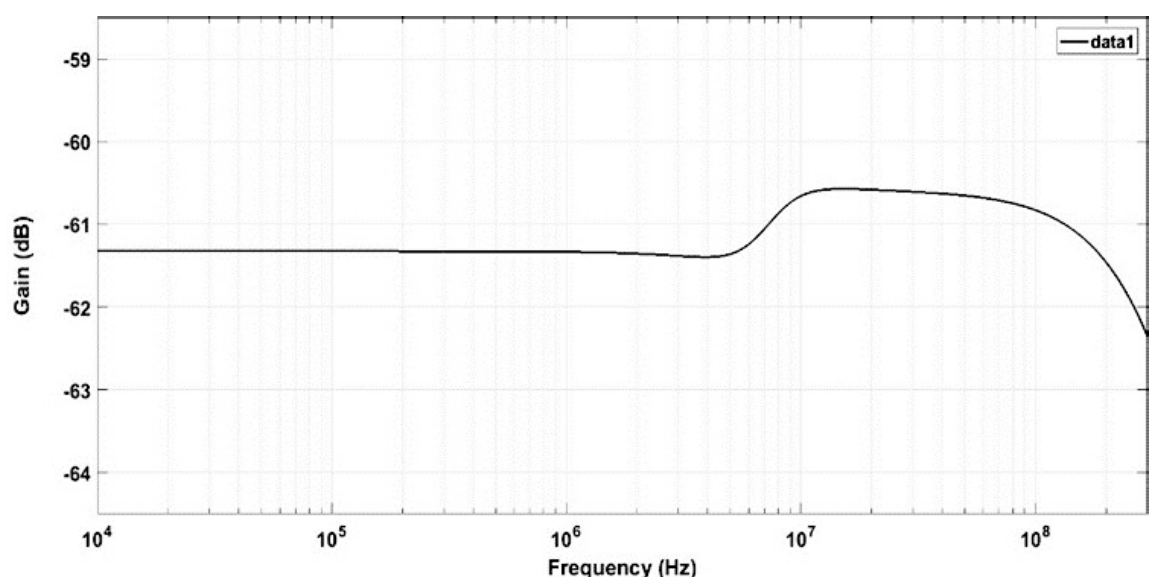

(a)

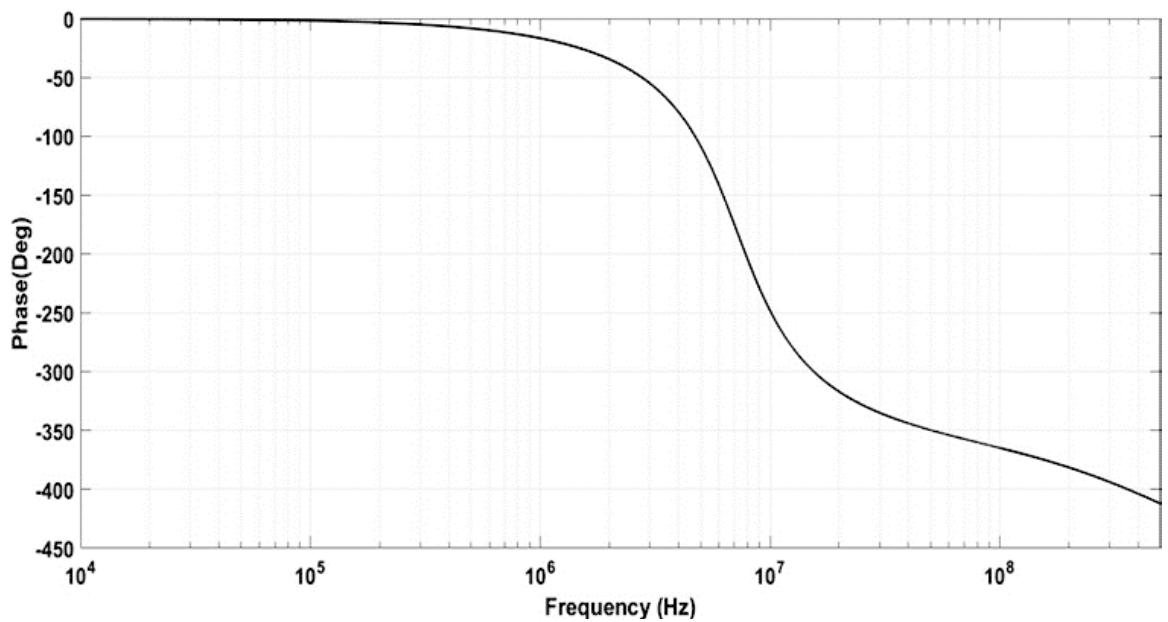

(b)

Figure 13. TAM all pass response of the dual mode filter: (a) magnitude; (b) phase.

The dual mode MISO CM and TIM filter employing three VDBAs presented in Figure 5 is validated by designing it for $-3 \mathrm{~dB}$ cutoff frequency of $4.562 \mathrm{MHz}$. According to Equations 20-21, the passive elements are selected as follows: $C_{1}=25 \mathrm{pF}, C_{2}=40 \mathrm{pF}$ and $R_{1}=1.1 \mathrm{k} \Omega$. The OTA bias current for all three VDBA is set at $100 \mu \mathrm{A}$ to achieve $g_{m(1-3)}$ $=906.53 \mu \mathrm{S}$. To design filter with unity gain, the condition of $\left(g_{m(2)} * R_{1}=1\right)$ must be satisfied. The ideal and postlayout frequency response of the current mode filter is given in Figure 14, and the AP response is shown in Figure 15. The power dissipation of the filter for bias current of $80 \mu \mathrm{A}$ for all three VDBAs is found to $5.49 \mathrm{~mW}$. 


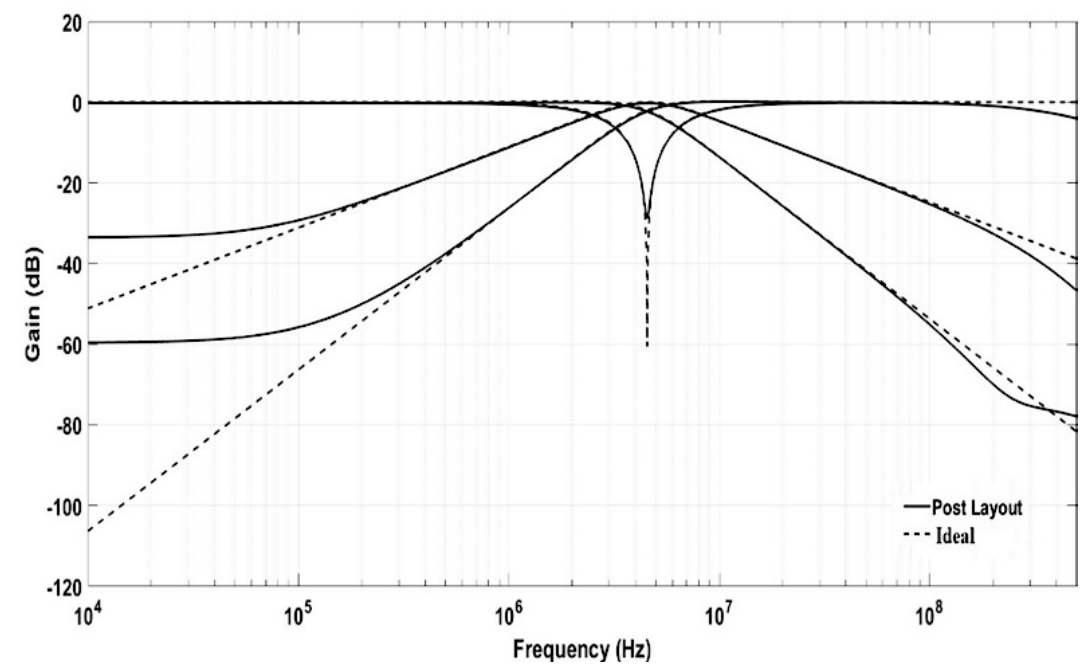

Figure 14. CM response of the dual mode filter.

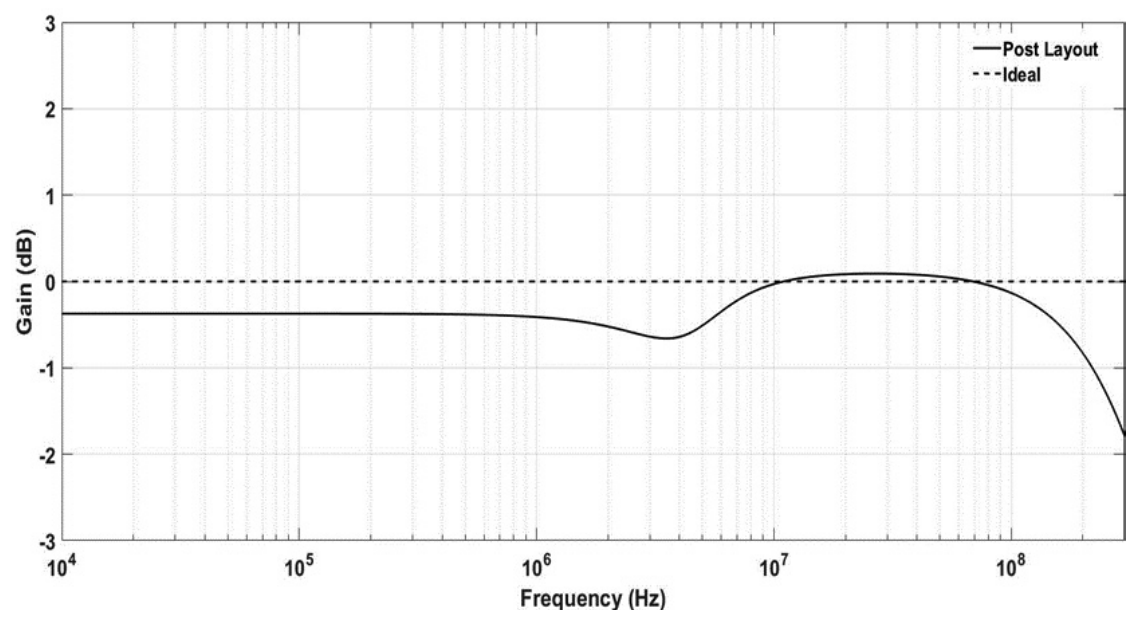

(a)

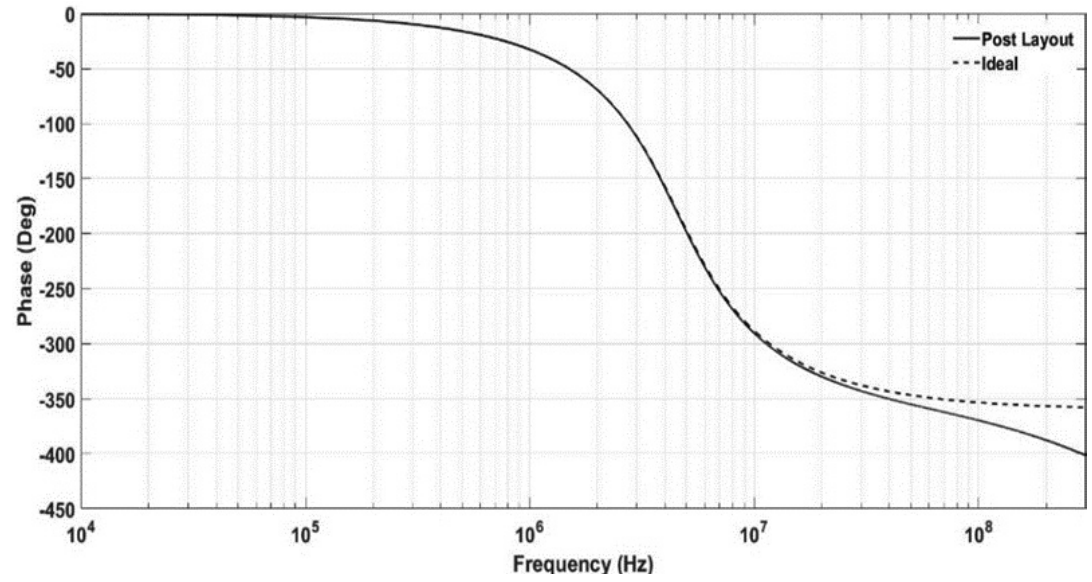

(b)

Figure 15. CM all pass response of the dual mode filter: (a) magnitude; (b) phase. 
To validate the signal processing capability of the filter transient analysis is carried out. A $100 \mu \mathrm{A}$ input signal at $4.562 \mathrm{MHz}$ frequency is applied and the BP output is observed. It can be inferred from Figure 16 the functions correctly.

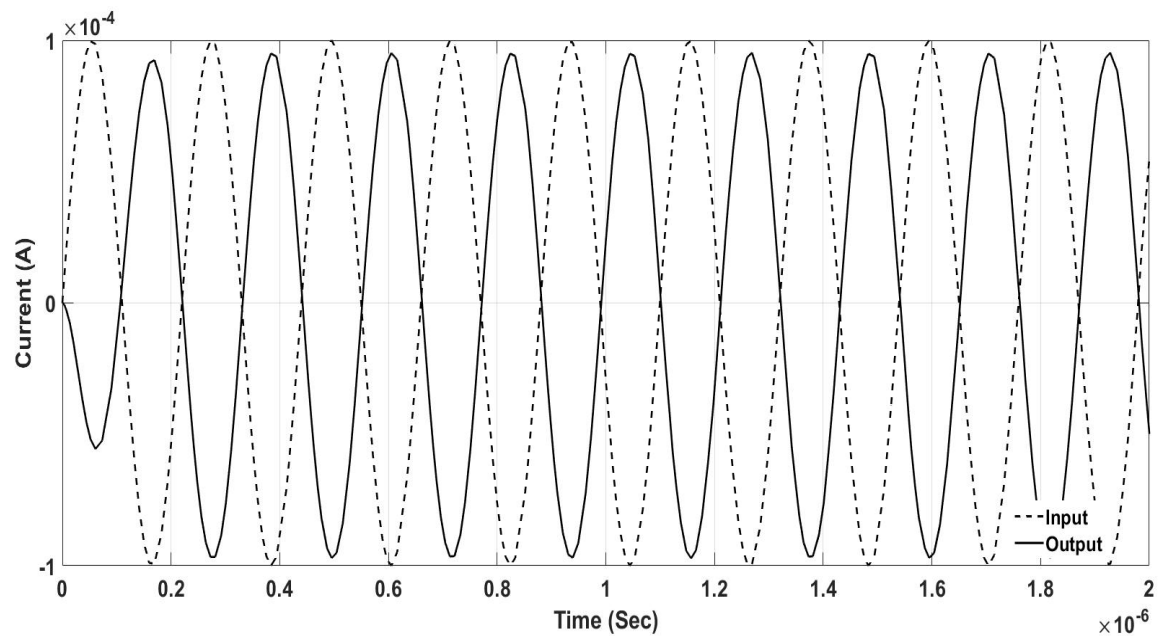

Figure 16. Transient analysis of the CM filter.

The TIM mode postlayout frequency response of the filter is presented in Figures 17-18 at the designed frequency of $4.562 \mathrm{MHz}$. This validates that the filter can work in dual mode simultaneously.

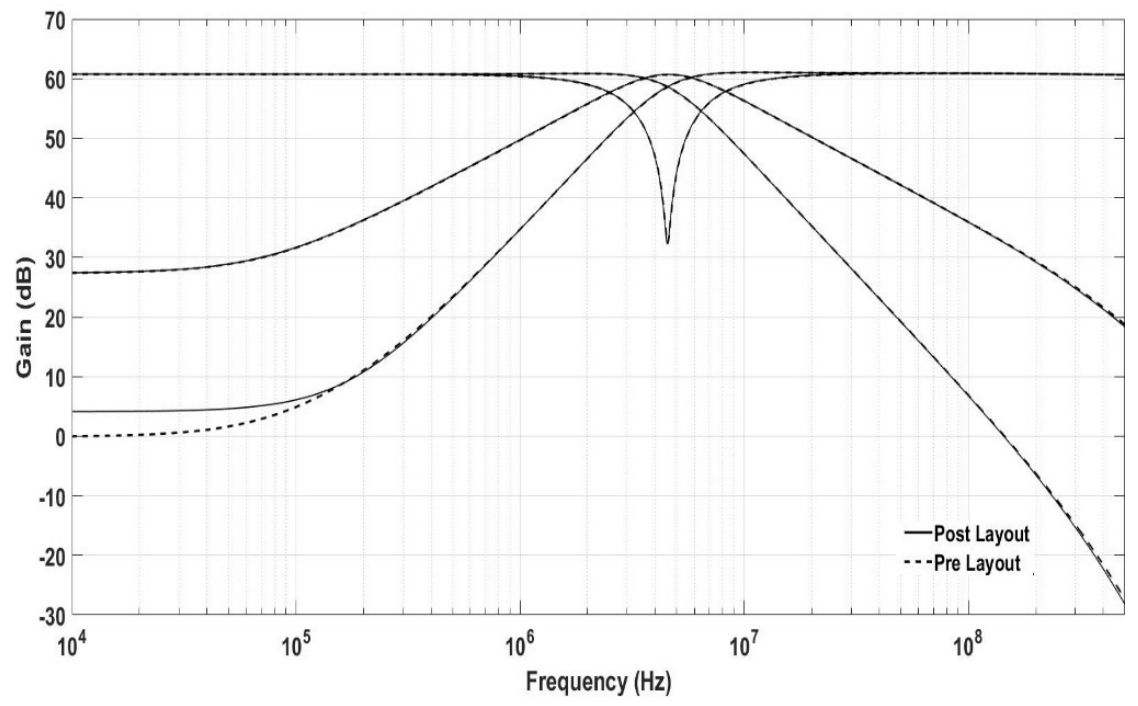

Figure 17. TIM response of the dual mode filter. 


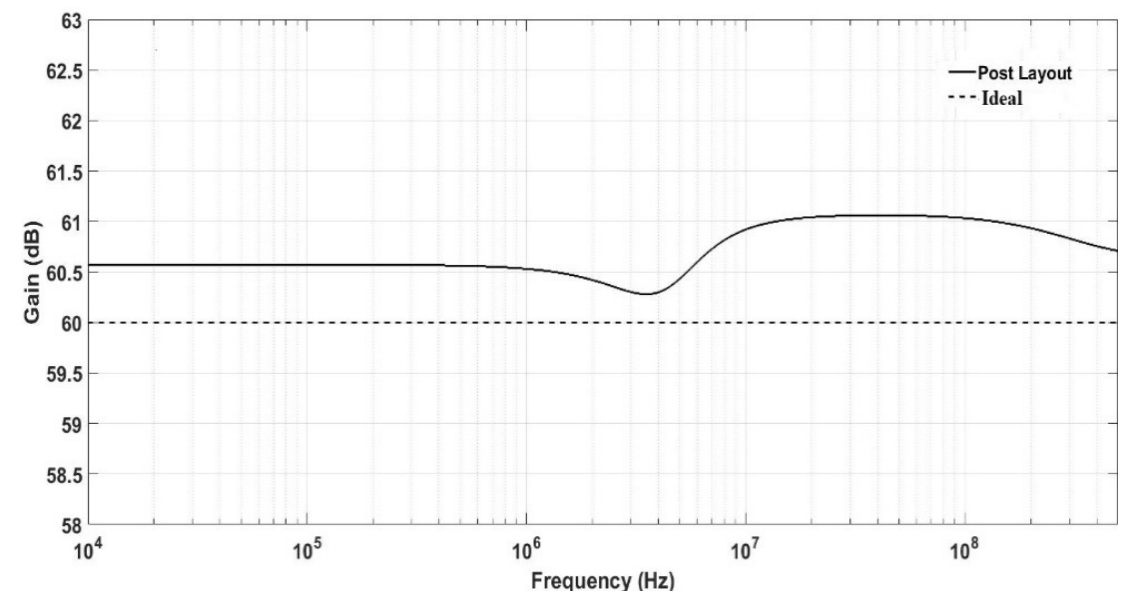

(a)

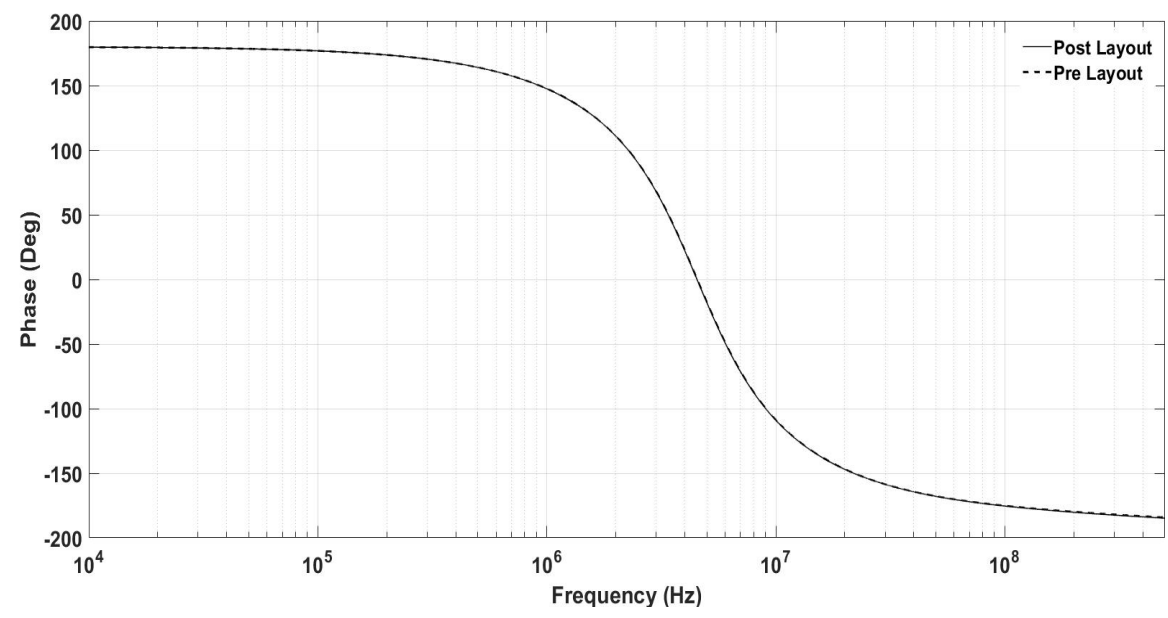

(b)

Figure 18. TIM all pass response of the dual mode filter: (a) magnitude; (b) phase.

The VM MISO filter employing single VDBA presented in Figure 6 is validated by designing it for $-3 \mathrm{~dB}$ cutoff frequency of 7.224 MHz. According to Equations 23-24 the passive elements are selected as follows $C_{1}=20 \mathrm{pF}$ and $C_{2}=20 \mathrm{pF}$. The transconductance of the VDBA is set at $g_{m(1)}=906.53 \mu \mathrm{S}$. The value of resistance is selected to be $R_{1}=1.1 \mathrm{k} \Omega$ to satisfy the condition of $\left(g_{m(1)} * R_{1}=1\right)$. The ideal and postlayout frequency response of the filter is given in Figure 19, and the AP phase response is shown in Figure 20. 


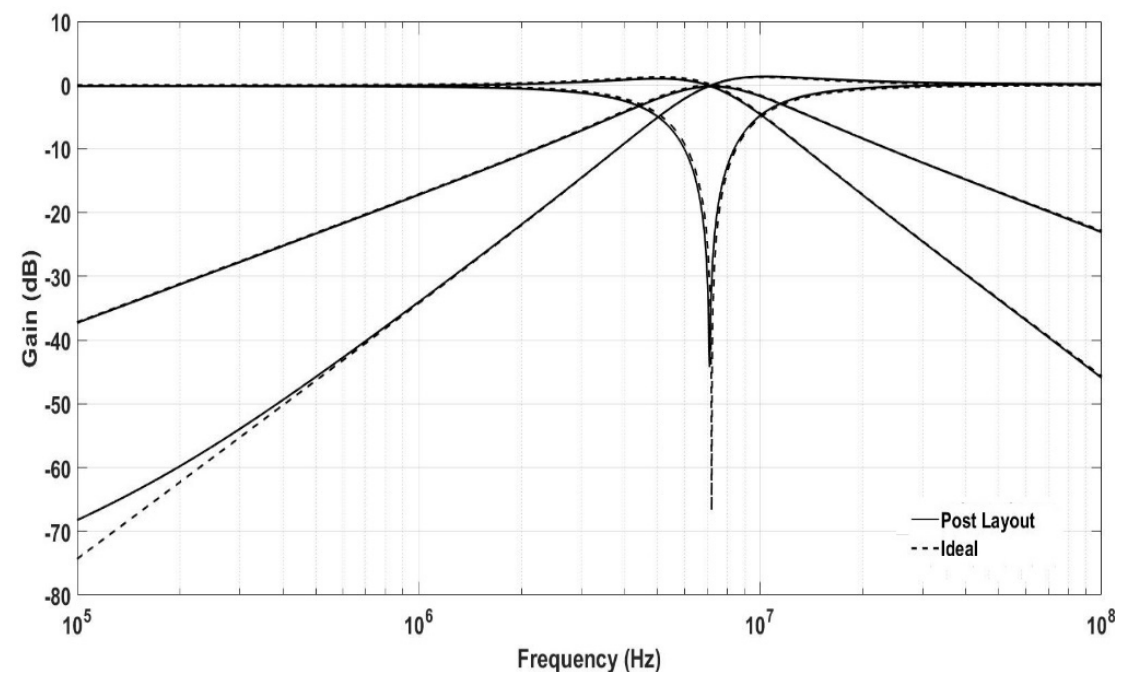

Figure 19. VM filter response.

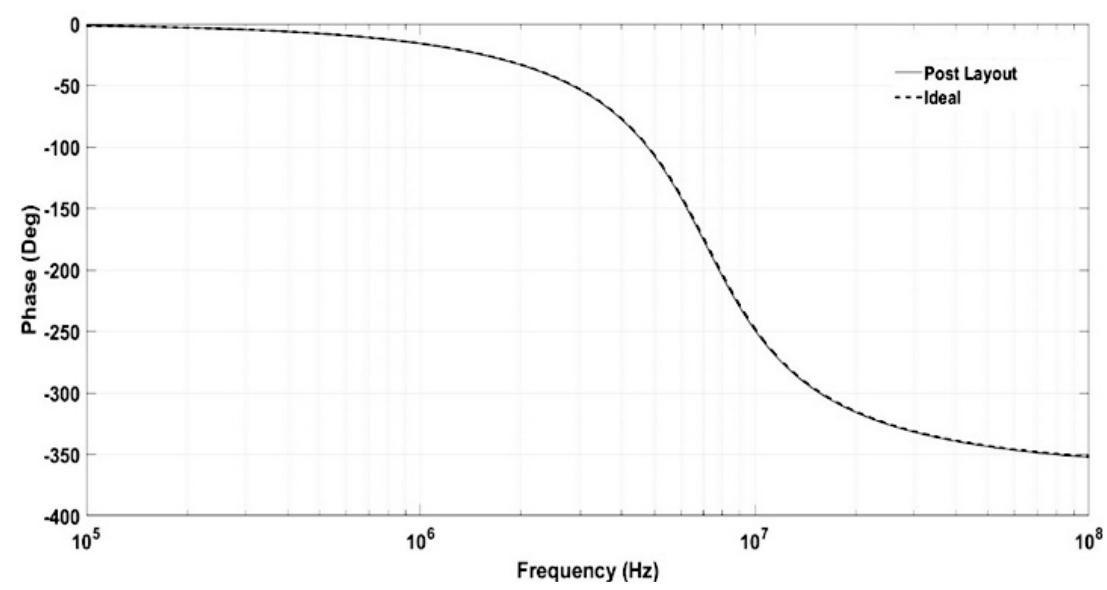

Figure 20. VM all pass phase response.

In order to bring out the merits of the proposed VDBA based filters they are compared with the other VDBA, VDIBA and VD-DIBA based filters since all of these have VDBA as core ABBs. The comparison is done based on the following criteria (i) Number active blocks employed (ii) number of passive elements used (iii) passive elements matching condition (iv) use of negative input for filter response realization (v) requirement of double input for filter response (vi) availability of output at low impedance node for VM and TIM and availability of output at high impedance node for CM and TAM (vii) number of modes realized (viii) independent control of quality factor and pole frequency (ix) test frequency and (x) can realize all five filter functions (xi) supply voltage (xii) power dissipation. The comparison is presented in Table 7. 
Table 7. Comparative study of VDBA based filters.

\begin{tabular}{|c|c|c|c|c|c|c|c|c|c|c|c|c|}
\hline Reference & (i) & (ii) & (iii) & (iv) & (v) & (vi) & (vii) & (viii) & (ix) & (x) & (xi) & (xii) \\
\hline $\begin{array}{c}\text { (Pushkar et } \\
\text { al. 2014) }\end{array}$ & 1 & 3 & No & No & No & No & VM & No & $\begin{array}{c}1.34 \\
\mathrm{MHz}\end{array}$ & Yes & $\pm 2 \mathrm{~V}$ & - \\
\hline $\begin{array}{c}\text { (Gupta et al. } \\
\text { 2015) }\end{array}$ & 2 & 2 & No & No & No & Yes & VM & No & $\begin{array}{c}12.9 \\
\mathrm{MHz}\end{array}$ & Yes & $\pm 0.75 \mathrm{~V}$ & $2.8 \mathrm{~mW}$ \\
\hline $\begin{array}{c}\text { (Sokmen et } \\
\text { al. 2016) }\end{array}$ & 2 & 2 & No & No & No & No & VM & Yes & $1 \mathrm{MHz}$ & No & $\pm 0.4 \mathrm{~V}$ & - \\
\hline $\begin{array}{c}\text { (Herencsar et } \\
\text { al. 2013) }\end{array}$ & 1 & 2 & No & No & No & No & VM & No & $\begin{array}{c}1.59 \\
\mathrm{MHz}\end{array}$ & Yes & $\pm 0.9 \mathrm{~V}$ & $10.5 \mathrm{~mW}$ \\
\hline $\begin{array}{c}\text { (Pushkar et } \\
\text { al. 2013) }\end{array}$ & 1 & 3 & Yes & No & Yes & Yes & VM & No & $\begin{array}{c}\mathrm{kHz} \\
\mathrm{Range}\end{array}$ & Yes & - & $10.5 \mathrm{~mW}$ \\
\hline $\begin{array}{c}\text { (Kaçar et al. } \\
\text { 2012) }\end{array}$ & 2 & 2 & No & Yes & No & Yes & VM & No & $\begin{array}{c}1.19 \\
\mathrm{MHz}\end{array}$ & Yes & $\pm 1.5 \mathrm{~V}$ & $1.94 \mathrm{~mW}$ \\
\hline $\begin{array}{c}\text { Authors Work } \\
\text { Figure 4 }\end{array}$ & 3 & 2 & No & No & No & Yes & $\begin{array}{c}\text { VM, } \\
\mathrm{TIM}\end{array}$ & Yes & $\begin{array}{c}8.315 \\
\mathrm{MHz}\end{array}$ & Yes & $\pm 1.25 \mathrm{~V}$ & $5.47 \mathrm{~mW}$ \\
\hline $\begin{array}{c}\text { Authors Work } \\
\text { Figure 5 }\end{array}$ & 3 & 3 & No & No & No & Yes & $\begin{array}{c}\mathrm{CM}, \\
\mathrm{TAM}\end{array}$ & No & $\begin{array}{c}5.193 \\
\mathrm{MHz}\end{array}$ & Yes & $\pm 1.25 \mathrm{~V}$ & $5.49 \mathrm{~mW}$ \\
\hline $\begin{array}{c}\text { Authors Work } \\
\text { Figure 6 }\end{array}$ & 1 & 3 & No & Yes & No & Yes & VM & No & $\begin{array}{c}7.8 \\
\mathrm{MHz}\end{array}$ & Yes & $\pm 1.25 \mathrm{~V}$ & $1.82 \mathrm{~mW}$ \\
\hline
\end{tabular}

It is clear from the table that the two dual mode filters proposed are the first ever reported VDBA based filters working in dual mode simultaneously. In addition, all the design provides voltage output at low impedance node and current output at high impedance node, which is an advantage over others.

\section{CONCLUSION}

In this research, three novel VDBA based universal filters are proposed. Two of the proposed filters can work in dual mode simultaneously. All the designed filters did not require any passive components matching and are cascadable. The complete layout of the VDBA is designed, and all the proposed filters are validated using the postlayout simulations. Additionally, the effect of nonideal frequency dependent voltage and transconductance transfer gains on the performance of the filter circuits is also studied. Furthermore, the sensitive analysis is also performed. Enough postlayout simulation results are provided to validate the correct functioning of proposed filters.

\section{ACKNOWLEDGMENT}

This work is funded by Ministry of Education Malaysia under grant (FRGS/1/2018/TK04/UKM/02/1) and AKU254:HICoE (Fasa II) 'MEMS for Biomedical Devices (artificial kidney)'.

\section{REFERENCES}

Abaci, A. \& Yuce, E. 2019. Single DDCC based new immittance function simulators employing only grounded passive elements and their applications. Microelectronics Journal, 83: 94-103.

Başak, M.E., 2019. Realization of DTMOS based CFTA and multiple input single output biquadratic filter application. AEUInternational Journal of Electronics and Communications, 106: 57-66.

Biolek, D. 2003. CDTA-building block for current-mode analog signal processing. In Proceedings of Proceedings of the ECCTD: 397-400. 
Biolkova, V., Kolka, Z. \& Biolek, D. 2009. Fully balanced voltage differencing buffered amplifier and its applications. In Proceedings of 52nd IEEE International Midwest Symposium on Circuits and Systems: 45-48.

Cheng, Y., \& Li, Y. 2015. The Design of Integrated Circuit for Biomedical and mHealth Application. In Mobile Health (pp.513537). Springer.

Faseehuddin, M., Sampe, J., Shireen, S. \& Ali, S.H.M. 2018. Lossy and lossless inductance simulators and universal filters employing a new versatile active block. Informacije MIDEM, 48: 97-113.

Garradhi, K., Hassen, N., Ettaghzouti, T. \& Besbes, K. 2018. Realization of current-mode biquadratic filter employing multiple output OTAs and MO-CCII. AEU-International Journal of Electronics and Communications, 83: 168-179.

Gupta, M., Srivastava, R. \& Singh, U. 2015. Low-voltage low-power FGMOS based VDIBA and its application as universal filter. Microelectronics Journal, 4: 125-134.

Herencsár, N., Koton, J., Vrba, K. \& Lattenberg, I. 2010. New voltage-mode universal filter and sinusoidal oscillator using only single DBTA. International Journal of Electronics, 97: 365-379.

Herencsar, N., Minaei, S., Koton, J., Yuce, E. \& Vrba, K. 2013. New resistorless and electronically tunable realization of dualoutput VM all-pass filter using VDIBA. Analog Integrated Circuits and Signal Processing, 74: 141-154.

Horng, J.W. \& Jhao, Z.Y. 2013. Voltage-mode universal biquadratic filter using single DVCC. ISRN Electronics.

Kaçar, F., Yesil, A. \& Noori, A. 2012. New CMOS realization of voltage differencing buffered amplifier and its biquad filter applications. Radioengineering, 21: 333-339.

Kumar, V., Mehra, R. \& Islam, A., 2019. Design and analysis of MISO bi-quad active filter. International Journal of Electronics, 106: $287-304$.

Lee, C.N. 2017. Independently tunable plus-type DDCC-based voltage-mode universal biquad filter with MISO and SIMO types. Microelectronics journal, 67: 71-81.

Mohan, P.A. 2012. Current-mode VLSI analog filters: design and applications, Springer Science \& Business Media.

Myderrizi, I., Minaei, S. \& Yuce, E. 2011. DXCCII-based grounded inductance simulators and filter applications. Microelectronics Journal, 42: 1074-1081.

Ninsraku, W., Biolek, D., Jaikla, W., Siripongdee, S. \& Suwanjan, P. 2014. Electronically controlled high input and low output impedance voltage mode multifunction filter with grounded capacitors. AEU-International Journal of Electronics and Communications, 68: 1239-1246.

Pandey, N. \& Paul, S.K. 2011. VM and CM universal filters based on single DVCCTA. Active and Passive Electronic Components.

Pushkar, K.L., Bhaskar, D.R. \& Prasad, D. 2014. Voltage-mode new universal biquad filter configuration using a single VDIBA. Circuits, Systems, and Signal Processing, 33: 275-285.

Pushkar, K.L., Bhaskar, D.R. \& Prasad, D. 2013. Voltage-mode universal biquad filter employing single voltage differencing differential input buffered amplifier. Circuits and Systems, 4: 44.

Ranjan, A., Perumalla, S., Kumar, R., John, V. \& Yumnam, S. 2018. Second Order Universal Filter Using Four Terminal Floating Nullor (FTFN). Journal of Circuits, Systems and Computers : 1950091.

Raut, R. \& Swamy, M.N. 2010. Modern analog filter analysis and design: a practical approach, John Wiley \& Sons.

Sagbas, M., Ayten, U.E. \& Sedef, H. 2010. Current and voltage transfer function filters using a single active device. IET circuits, devices \& systems, 4: 78-86.

Selvarajan, R.S., Hamzah, A.A., Zawawi, S.A. \& Majlis, B.Y. 2018. Optimisation of pattern transfer in fabrication of GFET for biosensing applications. In Proceedings of IEEE International Conference on Semiconductor Electronics (ICSE):156-159.

Senani, R., Bhaskar, D. \& Singh, A. 2014. Current conveyors: variants, applications and hardware implementations, Springer.

Singh, P. \& Nagaria, R.K., 2020. Electronically tunable DV-EXCCCII-based universal filter. International Journal of Electronics Letters, 1-17. 
Sokmen, O.G., Tekin, S.A., Ercan, H. \& Alci, M. 2016. A novel design of low-voltage VDIBA and filter application. Elektronika ir Elektrotechnika, 22: 51-56.

Tangsrirat, W. \& Channumsin, O. 2011. Voltage-mode multifunctional biquadratic filter using single DVCC and minimum number of passive elements.

Uttaphut, P. 2018. Single VDCC-based electronically tunable voltage-mode second order universal filter. Przegląd Elektrotechniczny : 94.

Yeşil, A., Kaçar, F. \& Gürkan, K. 2014. Lossless grounded inductance simulator employing single VDBA and its experimental band-pass filter application. AEU-International Journal of Electronics and Communications, 68: 143-150.

Yuce, E. \& Tez, S. 2018. A novel voltage-mode universal filter composed of two terminal active devices. AEU-International Journal of Electronics and Communications, 86: 202-209.

Yunus, F.W., Hamzah, A.A, Buyong, M.R., Yunas, J. \& Majlis, B.Y. 2017. Negative charge dielectrophoresis by using different radius of electrodes for biological particles. In Proceedings of IEEE Regional Symposium on Micro and Nanoelectronics (RSM):84-87. 